\title{
COLLABORATION AND TEACHER KNOWLEDGE IN A TEACHER LEARNING COMMUNITY: A CASE OF MATHEMATICS TEACHERS IN KWAZULU-NATAL PROVINCE
}

\author{
F-Q. B. Zulu* \\ e-mail: ZuluF1@ukzn.ac.za \\ C. Bertram* \\ e-mail: BertramC@ukzn.ac.za \\ *School of Education \\ University of KwaZulu-Natal \\ Pietermaritzburg, South Africa
}

\section{ABSTRACT}

The literature on professional development of teachers has shifted to focusing on collaboration and learning communities as a productive way for teachers to learn. This qualitative case study examines the nature of collaborative activities and the kinds of teacher knowledge learnt in a community of high school mathematics teachers. Data was collected through observations of professional development workshops, questionnaires, interviews with teachers and document analysis. The findings established that collegial collaboration and the focus on specialised content knowledge in this learning community enabled teachers to approach their teaching more effectively. In this article we claim that that the learning community is a productive learning space because it was supported by the Department of Education and a Non-Governmental Organisation, and because it focused on specialised content knowledge. The collaborative focus enabled teachers to share knowledge and ideas resulting in teachers taking charge of their own learning.

Keywords: teacher learning community, collaborative activities, Mathematics teaching, teacher knowledge, specialised content knowledge

\section{INTRODUCTION}

Increasing research on professional development models sees teacher collaboration as an effective forum for teachers to access professional development opportunities close to their places of work (Kennedy 2005; Pirtle 2014; Avalos 2011). "Collaboration is thus very important for professional development as it not only provides the necessary support for learning but also provides teachers with feedback and brings about new ideas and challenges" (Kwakman 2003, 152). According to Kwakman (2003) collaboration of teachers involves intensive interactions in which teachers together engage in activities that facilitate learning. 
However, understanding the nature of collaborative activities and what is learnt from collaborative activities is still limited in South Africa especially in a rural context. There is some literature (Jita and Mokhele 2014; Brodie and Borko 2016) on teacher collaboration which explores the formal collaboration required by the Department of Basic Education (DBE) on school-based collaborative structures. This study explores the nature of the collaborative activities of a group of mathematics teachers from a number of schools in a selected circuit where professional development workshops were offered by a Non-Governmental Organisation (NGO) in partnership with the DBE. The kinds of knowledge acquired from these collaborative activities is also explored. In this study collaborative activities refers to the formal and informal activities in which the selected group of high school mathematics teachers engage in during and outside of the workshops. The research questions of this study are: 1 . What is the nature of collaborative activities in the mathematics teacher learning community (TLC)? 2. What type of teacher knowledge is acquired from these collaborative activities?

The following section presents literature on teacher collaboration, teacher learning communities and teacher knowledge. This is followed by the description of the research methodology, and the findings and discussion. Finally, the last section concludes the article with a discussion of the implications of the findings and recommendations.

\section{CONCEPTUALIZATION OF TEACHER COLLABORATION, TEACHER} LEARNING COMMUNITIES AND TEACHER KNOWLEDGE

The concept of collaboration is overused and its real meaning remains unclear. Several authors such as Hargreaves (1994), Forte and Flores (2014), Robutti et al. (2016) have drawn attention to the ambiguity and complexity of the meaning of "collaboration" and misuse of it as a synonym of "cooperation". Robutti et al. (2016) point out, "collaborate means to work jointly with and cooperation indicates that individuals contribute to various aspects of a particular task" (2016, 652). Robutti et al. (2016) further suggest that these terms are related with regard to describing joint activities of individuals or institutions. Forte and Flores (2014), argue that "collaboration" involves developmental activities with consequences for several people going beyond the superficial exchange of help, support, or assistance. In line with the literature, collaboration in this study involves sharing and interaction "going a step beyond mere cooperation" (Forte and Flores 2014, 92).

There is a growing belief that collaboration is essential for teachers because it enables them to share practices and perspectives with colleagues which can create new possibilities for learning (Dixon, Reed and Reid 2013, 1103). The DBE (2015) supports the establishment of professional learning communities as a way of encouraging teacher collaboration and 
strengthening teacher professionalism. This is in line with findings in international literature on teacher "continuing professional development" (CPD) which describes various structures such as teachers' subject clusters, "communities of practice" (CoP) and "teachers learning communities" (TLCs) which are also sometimes called "professional learning communities" (PLCs). It is argued that these structures are used to support teachers' collaborative professional learning (Butler, Schenellert and MacNeil 2015; Maistry 2008; Jita and Mokhele 2014; Bantwini 2018). Pirtle (2014) have pointed out that the term PLCs has become overused and the meaning is often lost. This study therefore uses the term "teacher learning community" to describe the group of mathematics teachers who met on a regular basis, as organised by the NGO. Teacher learning communities "embody the concept of teacher learning in a setting in which teachers come together over time for the purpose of reconsidering their existing beliefs and practice, gaining new professional knowledge and skills and reconstructing reform agendas that enhance student learning and professional practice" (Chow 2015, 288). The literature shows that teacher groups can only be regarded as PLCs when they adhere to a particular set of practices which includes collaborative learning, reflecting on their practice, meeting regularly, shared leadership, collective responsibilities and collective decision making (Pirtle 2014, 1). The focus of this study was not to ascertain if the group of teachers reflected these characteristics of a PLC, thus we use the term teacher learning community to refer to this group of mathematics teachers. William (2007) maintains that TLCs do not include administrators and other professionals, although these stakeholders can provide TLCs with support and advocacy of the group, which was the case in the mathematics group. William (2007) further contends that TLCs are only those groups of teachers who learn and attempt to make changes in their classroom practice.

Hargreaves (1994) identifies two cultures in which collaboration occurs in different structures: namely "collaborative cultures" and "a culture of contrived collegiality". He describes a collaborative culture "as typically involving working relationship between teachers and their colleagues which tend to be spontaneous, voluntary, development -oriented, pervasive across time and space and unpredictable" (Hargreaves 1994, 192). In contrast, the culture of contrived collegiality involves administrative regulation, compulsion, an implementationorientation, fixed location time and space, and predictability (1994, 195-196). Hargreaves (1994) is in favour of collegial interaction as the most important aspect of collaboration. While Hargreaves (1994) argues for a collaborative culture that is development-orientated, Day (1999) claims that these two cultures work together in that a culture of contrived collegiality may act as a prompt towards more collaborative cultures in providing added chances for development. In the South African context, this linking of contrived collegiality and collaborative culture 
relates to transforming a cluster from administratively-regulated teacher collaboration to a teacher-driven collaborative learning space, which is the case for this group of mathematics teachers who were the subject of the research.

Existing South African literature on teacher collaboration such as Brodie and Borko (2016) and Bantwini (2018) seem to focus on teacher collaboration through teachers learning in TLCs and professional learning communities (PLCs) that are operating within schools. The findings of one of these studies suggest that "success in establishing sustained teacher collaboration requires that the teachers have a broad range of support personnel, internally and externally, whom they can consult on various issues pertaining to their teaching practices" (Bantwini 2018, 15). Furthermore, collaboration of teachers within schools is also promoted in South African education policy, namely the Integrated Strategic Planning Framework for Teacher Education and Development (DBE and Department of Higher Education (DHET) 2011). According to this policy, the DBE and DHET envisage that support and resources for teachers, and access to professional development opportunities, "will be enhanced at local level by the establishment of PLCs" (DBE and DHET 2011, 10). Studies done of cluster groups (teacher's groups initiated by DBE for administrative purposes) and teacher learning communities (Graven 2002; Jita and Ndlalane 2009; Jita and Mokhele 2014; De Clercq and Phiri 2013) indicate on the benefits of teacher collaboration. For example, a study on teacher learning communities in a South African context have established that through collaborative learning teachers developed confidence that was essential to their professional development (Graven 2002).

In an international context, Schnellert, Butler and Higginson, (2008) studied six teachers in one Canadian school, where collaborative learning of six teacher was supported by university researchers. The findings of this study indicate that the collaboration of the six teachers enabled them to use learning tools designed to develop and measure the progress in literacy skills among students. According to Schnellert et al. (2008) the six teachers were able to meet part of the Canadian policy target called Learning through Reading. A group of researchers in Scotland, Priestley et al. (2011) and Butler, Schnellert and MacNeil (2015) in Canada have focused on TLCs that are outside of the school. These two international studies report that teachers engaged in TLC activities among other things as a way of sharing ideas and thinking about their own professional development in relation to the education policy. The findings of these two studies appear to suggest that teacher collaboration was characterised by "compulsion" (Hargreaves 1994, 195-196) to meet the policy target, a mandated agenda of the education system. Although the positive results of collaboration are reported in the above mentioned studies, Chen, Elchert and Asikin-Garmager (2018) highlight that teachers do not always like the opportunity to work 
together to share teaching practices "particularly when collaboration practice is a result of a top-down mandate and tied to staff appraisal" $(2018,4)$.

Teacher knowledge and collaboration are related in that collaborative activities in which teachers engage in may result in learning that enables teachers to develop or enhance their professional knowledge. Professional knowledge is defined as "a body of knowledge and skills needed in order to function successfully in a particular profession" (Chauraya and Brodie 2018, 223). In line with this study the knowledge needed is to teach mathematics is divided into five components namely; "common content knowledge, specialised content knowledge, knowledge of content and students, knowledge of content and teaching, knowledge of content and curriculum horizon" (Ball, Thames and Phelps 2008, 399). These scholars have aligned domains of teacher knowledge to mathematics by refining and expanding on Shulman's (1987) subject content knowledge and pedagogical content knowledge (PCK). Shulman (1987) describes PCK as a combination of subject matter knowledge and pedagogical knowledge. Elaborating from Shulman's (1987) notion of PCK, Ball et al. (2008) and Hurrel (2013) claim that PCK is the combination of content knowledge with one or more categories of Shulman's domains of teacher knowledge.

Common Content Knowledge (CCK): Ball et al. (2008) state that CCK is not specific to teaching but it is a subject-specific knowledge needed to solve mathematics problems. An example of CCK in arithmetic algebra is $10 \times 10=100$. These scholars maintain that this knowledge is critically important for teachers because it is difficult to teach without common sense or to teach what one does not know.

Specialised Content Knowledge (SCK): According to Ball et al. (2008), SCK is defined as mathematical knowledge and skills unique to teaching. "Teachers need to have a specialized understanding of, for example, how $(x+y)^{2}$ can be expanded" (Ball et al. 2008, 400). SCK enables the teachers to understand learners' strategies and sources of error better and it also includes knowledge of representing mathematical procedures and ideas using pictures and manipulatives. The understanding of learners' strategies and error is in line with Shulman's notion of PCK.

Knowledge of content and students (KCS): According to Ball et al. (2008), KCS allows an interaction between specific mathematical understanding with students and their mathematical thinking (Ball et al. 2008, 400). For example, they say that in exponents, a teacher's KCS enables the teacher to expect students to incorrectly think that $(x+y)^{2}=x^{2}+y^{2}$ and to anticipate misconceptions about the distributive property and exponents.

Knowledge of content and teaching (KCT): In line with Shulman's (1987) description of PCK that it is the amalgamation of pedagogical and content knowledge, Ball et al. (2008) state 
that $\mathrm{KCT}$ integrate knowing about teaching and knowing about mathematics. However, Ball et al. (2008) clarify that in relation to mathematics, knowledge of content and teaching is a combination involving a specific mathematical idea or procedure in addition to familiarity with pedagogical principles for teaching that specific content.

Knowledge of content and curriculum (KCS)/(Horizon): Knowledge about content and curriculum means "teachers' knowledge of the available materials that they can use to support students' learning" (Ball et al. 2008, 401). The mathematics teachers drew upon their knowledge to decide which textbooks are best for teaching geometry and algebra for a certain grade. Knowledge of the curriculum is part of the mathematics content knowledge domain and it is an advanced background of the subject matter of the mathematics (Krauss and Blum 2012). Generally, a curriculum policy is essentially a course of study or plan of what must be taught and learnt. The Curriculum and Assessment Policy Statement (CAPS) is the curriculum that South African teachers currently need to follow and know. This study was undertaken when CAPS was introduced in 2012 in Grade 10. During the data collection stage in 2013, CAPS was introduced in Grade 11. So the curriculum knowledge in this study is based on CAPS.

South African studies on teachers' mathematical knowledge such as that of Pournara et al. (2015) have established that many teachers in South Africa lack subject content knowledge. The research literature and DBE and DHET suggest that collaboration of teachers is a solution to the problem of the shortage of professional development opportunities. This study therefore contributes to this on-going discussion about teacher collaboration by examining the nature of collaborative activities and the types of knowledge that is learnt in a TLC located in a rural part of South Africa.

\section{THE STUDY CONTEXT}

This study was conducted on a mathematical TLC in the Zethembe (pseudonym) DBE district in KwaZulu-Natal. This study focussed on mathematics teachers who are teaching in the Further Education and Training (Grades 10-12) level (Zulu 2017). Zethembe District is more disadvantaged than the other 11 districts of KwaZulu-Natal because the majority of schools are in rural areas spread out over a very wide area. The schools are grouped into 4 circuits and each circuit has approximately 20 high schools. The mathematics TLC is a group of 25 high school mathematics teachers teaching within one circuit. This mathematics TLC was formed as one of the teachers' clusters initiated by the DBE. In 2007, an NGO became involved in the mathematics TLC in an attempt to address the crisis in the teaching and learning of mathematics. (NGO's Evaluation Report of Mathematics project, 2012). The NGO supported the mathematics TLC by providing funding, resources and facilitating workshops. The NGO workshops are facilitated by teachers from the NGO. 


\section{RESEARCH METHODOLOGY}

An interpretive case study research design was used with an aim of investigating teachers' collaboration within a limited and focused setting (Rule and John 2011). Purposive sampling was used to select a case, and interview participants. The interview sample group comprised four participants: Hlengiwe, the cluster coordinator and a lead teacher; Jabulani, a lead teacher; Bongani, a lead teacher; and Siza, the NGO facilitator. The participants were given pseudonyms. These three teachers and the NGO facilitator who were seen as having in-depth knowledge about the mathematics TLC by "virtue of their professional role, expertise and experience" (Cohen, Manion and Morrison 2007, 115) were interviewed. Data was also generated from three unstructured observations of the workshops; two were audio recorded and a one was video recorded. These three observations were aimed at reading behaviour patterns of participants during their meetings and workshops without unnecessary questioning or communication (Cohen et al. 2007). The observation notes and the attendance registers reports that there were approximately 14 teachers out of the 25 who attended the three workshops which were observed for data gathering purposes.

In addition, data on the collaborative activities and the kinds of knowledge learnt from these collaborative activities also comes from survey questionnaires administered in the last moderation meeting held on 22nd of October 2014. There were 25 questionnaires issued, and 19 participants responded to the questionnaires, which is 76 per cent response rate. These 19 participants comprised four female and 15 male teachers. The return rate of the questionnaires was very high when compared to the number of the mathematics teachers (14 teachers) who were in the three workshops that were observed and videotaped. Of the 19 teachers who completed the questionnaire, 26 per cent were novice teachers who had been teaching for 1-5 years and half had been teaching for more than 10 years. 31.6 per cent of the 19 participants have professional Diplomas, 10.5 per cent are teachers with degrees and teaching diplomas, and 36.8 per cent of teachers have teachers' professional degrees. All were teaching Grade 10, 11 or 12 mathematics.

Analysis of documents such as attendance registers, annual reports, constitutions, and minutes of meetings, agendas, funding documents and documents distributed at the workshops supplemented the other three data generation tools.

Thematic analysis was used to analyse the transcribed qualitative data from semistructured interviews and observations from audiotape and videotape. The open-ended responses from the questionnaire were also thematically analysed, while the closed-ended responses were analysed statistically. Additionally, Table 1 is the analytical tool that Zulu 
(2017) refined from the Mathematics domains of teacher knowledge in response to Hill and Lubienskie's (2007) claim that knowledge of content and curriculum and horizon content knowledge are incomplete they needs refinement and revision because they run across several categories.

Table 1: Ball et al. (2008) domains of teacher knowledge and revised Hurrell's (2013) supporting questions (Zulu 2017)

\begin{tabular}{|c|c|}
\hline Domain & To what extent do collaborative activities develop teachers' knowledge to: \\
\hline $\begin{array}{l}\text { Common Content } \\
\text { Knowledge (CCK) }\end{array}$ & $\begin{array}{l}\text { Calculate answers correctly. } \\
\text { Solve mathematical problems. } \\
\text { Use terms and notations correctly }\end{array}$ \\
\hline $\begin{array}{l}\text { Specialised } \\
\text { Content Knowledge } \\
\text { (SCK) }\end{array}$ & $\begin{array}{l}\text { Present mathematical ideas. } \\
\text { Respond to learners' why questions } \\
\text { Find examples/analogies/demonstrations/resources to make a specific mathematical } \\
\text { explanation. } \\
\text { Recognise what is involved in using a particular representation } \\
\text { Appraise and adapt the mathematical content of the textbook. } \\
\text { Modify tasks to be either easier or harder. } \\
\text { Give or evaluate mathematical explanations. } \\
\text { Choose and develop useable definitions. } \\
\text { Use mathematical notation and language, and critique its use. } \\
\text { Ask productive mathematical questions. } \\
\text { Select representations for particular purposes. }\end{array}$ \\
\hline $\begin{array}{l}\text { Knowledge of } \\
\text { Content and } \\
\text { Students/Teaching } \\
\text { (KCS/KCT) }\end{array}$ & $\begin{array}{l}\text { Anticipate what learners will find easy or difficult about completing a task. } \\
\text { Recognise the misconceptions that learners have and common errors that students } \\
\text { make. }\end{array}$ \\
\hline $\begin{array}{l}\text { Knowledge of } \\
\text { Content and } \\
\text { Curriculum } \\
\text { Horizon }(\mathrm{KCCH})\end{array}$ & $\begin{array}{l}\text { Understand the topic and purpose of the curriculum. } \\
\text { Make connections across the topics in the Mathematics curriculum. } \\
\text { Link representation to underlying ideas and to other representations. } \\
\text { Articulate how the Mathematics you teach fits into Mathematics which comes later. }\end{array}$ \\
\hline
\end{tabular}

The analytical tool was refined by combining knowledge of content and curriculum and horizon content knowledge because they both focus on the curriculum and content. The knowledge of content and curriculum involves teacher knowledge about mathematics content in relation to the curriculum and the available resources such as textbooks that might be used to support students learning. According to Hurrell's (2013) horizon content knowledge also involves teachers' knowledge of how mathematics topics are related over the span of the mathematics course included in the curriculum (Ball et al. 2008). These two domains of teacher knowledge both run across the content knowledge. This situation suggests that mathematics teachers cannot pace their teaching or relate different topics to content covered in earlier grades or to work still to come without knowledge of the curriculum as a whole because it states what must be taught in each particular grade. Therefore, "different forms of teacher knowledge may not be easily separable from one another" (Brodie and Sanni 2014, 190). Zulu (2017) argues that since PCK is contained in the specialised content knowledge it was not necessary to categorize it individually in the analytical tool. Hurrell (2013) constructed supporting questions based upon Ball et al.'s (2008) domains of teacher knowledge. These questions may be used to ascertain 
where professional development might be required. These supporting questions were revised and were used during data analysis to trace types of teacher knowledge that were acquired through collaboration by the selected mathematics teachers.

\section{FINDINGS}

This section presents the findings of the study and discusses the nature of the collaborative activities in which the mathematics teachers engaged, the extent of the collaborative activities and the kinds of teacher knowledge that were learnt from the collaborative activities.

\section{Nature of collaborative activities in the Mathematics TLC}

The data on the nature of the collaborative activities largely comes from the survey questionnaire that was administered during the moderation meeting. Considering that teacher collaboration can be formal and informal, descriptions of collaborative activities in this study are on two aspects: the nature of the collaborative activities during the workshops and the nature of the collaborative activities outside of the workshops.

\section{Nature of collaborative activities during the workshops}

The survey findings reveal that the mathematics teachers' collaboration during the workshops focussed on three collaborative activities. The majority of respondents $(78.9 \%)$ of 19 teachers stated that during the workshops they share ideas with other teachers about how to teach particular mathematics topics such as differentiation, work with other teachers to solve problems related to the subject content $(73.7 \%)$ and share teaching resources $(47.4 \%)$. The percentages do not add up 100 per cent because respondent were free to select more than one option. The observation data confirms that teachers were working with other teachers to solve problems related to subject content. This is shown in the following observation extract where the teachers were engaged with an algebra programming task:

Hlengiwe (cluster coordinator): "The way I understood it, it should be half per $\mathrm{kg}$ and half per $\mathrm{kg}$ is connected with the given information."

Jabulani (lead teacher): "Hlengiwe, elaborate."

Hlengiwe: "I am emphasising the point of half half."

All teachers: "It should be half half."

Teacher 2: "Guys, lets us come up with constraints and form the equation."

Teacher 1: "At most it is represented by $1 / 2 \mathrm{x}+1 / 3 \mathrm{y}$."

Teacher 2: "Next constraint is $1 / 2 \mathrm{x}+2 / 3 \mathrm{x} \leq 125$. This is what confuses learners, let us rather do it on the table for learners not to be confused."

Hlengiwe: "Then 5.2 , is $\mathrm{P}=5 \mathrm{x}+4 \mathrm{y}$ profit." 
In the above observation extract the teachers were discussing how to teach differentiation in a way that will be easy for the learners to understand. The three teachers who were interviewed also reported that they collaborated during the workshops on devising methods of how to teach a particular topic with relevant resources. Bongani spoke about the structure of the workshops and the nature of tasks that teachers do during the workshop:

"We get into small groups and discuss as educators how we could teach our learners with the material from NGO facilitator. We then all combine to discuss the material and come up with ways of how we could teach it to our learners. It's not only about learning a new thing. However, we learn various ways of imparting the material to the learners. So as educators we have various ways of imparting the material to the learners. From one educator you can learn different ways of imparting the same information in different ways to learners."

This quote indicates that the 14 mathematics teachers talk among themselves about teaching strategies and how to use the material which is prepared by the facilitator. The finding also reports on the collaboration observed during the moderation of learners' work for continuous assessment (CASS) where teachers check each other's marking. The following observation extract shows how Mpilo, the mathematics subject advisor, explains to the teachers how to check each other's work:

"Check that the educator has marked tasks according to the memorandum and the rubric; moderate all tasks in the learners' portfolio."

This collaborative activity is part of the administrative agenda of the DBE. Hargreaves (1994) refers to this type of collaboration as contrived collaboration, as it is not really a collaborative learning activity. Kwakman (2003) contends that this kind of collaboration does not always lead to learning (but they are learning how to assess learners' work more accurately).

\section{Nature of collaborative activities outside of the workshops}

There is evidence from survey findings that suggest that mathematics teachers use various strategies to support one another outside of the workshops. This is shown in Table 2.

Table 2: Respondents' views about the type of support outside of workshops $(N=19)$

\begin{tabular}{|l|c|c|}
\hline \multicolumn{1}{|c|}{ Type of collaborative activities outside of the workshops } & $\begin{array}{c}\text { No. of } \\
\text { Respondents }\end{array}$ & $\begin{array}{c}\text { Percentage of } \\
\text { Respondents }\end{array}$ \\
\hline Share teaching resources and activities. & 11 & 57,9 \\
\hline Share tests and examination papers & 14 & 73,7 \\
\hline Plan together different ways to teach particular topics & 12 & 63,2 \\
\hline
\end{tabular}




\begin{tabular}{|l|c|c|}
\hline \multicolumn{1}{|c|}{ Type of collaborative activities outside of the workshops } & $\begin{array}{c}\text { No. of } \\
\text { Respondents }\end{array}$ & $\begin{array}{c}\text { Percentage of } \\
\text { Respondents }\end{array}$ \\
\hline Design tests and examination together. & 10 & 52,6 \\
\hline Observe one another teaching in order to develop practice & 9 & 47,4 \\
\hline Moderate each other's learners' assessment tasks & 13 & 68,4 \\
\hline Other & 1 & 5,3 \\
\hline
\end{tabular}

Table 2 shows that 11 of the 19 participants share teaching resources consisting of textbooks, worksheets and activities, while 13 participants share tests and examination papers. Additionally, 12 participants support each other by working together to plan different ways in which to teach a particular topic. There are 10 of the 19 participants who work together to design tests and examinations. There are also 9 participants who observe one another teaching in order to develop their teaching practice. There is a significant number, 13 participants, who responded that they support each other by moderating each other's learners' tests and assignments and one participant uses other methods but he did not specify those methods. Other evidence from the interviews reveals that teacher collaboration took place outside of the workshop, Jabulani explains:

\footnotetext{
"We keep in contact with each other. For example, if you have a particular problem at your school in terms of the subject content. We go as members of the group to your school to help out. We once formed a group in 2011 whereby we had to visit each other's schools. That group consisted of only four members. We would go to the other members' school and teach. We would divide the topics amongst ourselves. We would then take turns when teaching, when the first one is done with a certain topic, the next steps in with a new topic. While the other one is in front teaching, the other three are going around the classroom giving the learners individual attention if they raise their hands of course. We do not just do it to the members of the small group we formed but with the other schools of the other members as well. If a member has a problem they ask us to come and they make arrangements with his or her school for our coming."
}

This interview extract seems to suggest that a collaborative culture (Hargreaves 1994) prevailed in the mathematics TLC members because this collaborative activity was initiated and driven by teachers and not by the NGO facilitator or their mathematics subject advisor. There is a high level of trust amongst teachers for them to team teach together. This trust was developed in the NGO workshops. Furthermore, the findings from the interview data also suggest that the collaborative activities that they initiated outside of the workshops enabled teachers to support one another through team-teaching and observing each other teaching to learn from one another.

\section{Regularity of teacher collaboration in the mathematics TLC}

This section looks at how often teachers collaborate during and outside of the workshop. Considering the physical distances between schools in the circuit it seems that the workshops 
held in the central venues offer teachers an opportunity for collaboration. The mathematics TLC runs several workshops annually which are facilitated by the mathematics subject advisor, the NGO facilitator and the mathematics teachers themselves. The DBE CASS moderation takes place once a term. The NGO workshops are run twice or thrice per term in the education centre in a circuit. There are also four-day holidays workshops held at the premises of the NGO (NGO Evaluation Report 2012). However, the workshop that were held in the NGO institution were not observed. The evidence from interviews suggests there is cooperation between the NGO and the KZN DBE regarding the facilitation of mathematics content workshops by the NGO facilitator. As for the extent of collaboration amongst the teachers outside of the workshops, the findings show that 47 per cent of teachers said that they collaborate with one another at least once a week and 20 per cent collaborate about once a month. A quarter of teachers responded by saying that their collaboration is not very much, as they only meet at workshops. Ten per cent of teachers indicated that they do not meet at all outside of the workshops. The general picture about the extent of collaboration between the mathematics teachers is that 40 per cent of teachers in this group collaborate during the workshops and outside of the workshops at least once a week. This seems to indicate that the teachers are not only relying on the externallyorganised workshops, but are also initiating their own collaborative learning activities.

\section{Kinds of mathematics knowledge learnt from collaborative activities}

It is not sufficient to only describe the form of the collaborative activities, we also need to engage with the substance of these activities, that is to say, what knowledge is acquired and shared through these activities. Ball et al.'s (2008) domains of teacher knowledge and Hurrell's (2013) revised supporting questions were used to describe the kinds of teacher knowledge that is acquired in the mathematics TLC.

Classification and examples of the kinds of knowledge according to the four domains of mathematics teacher knowledge are depicted in the following Table 3.

Table 3: Types of knowledge learnt in the Mathematics TLC (Zulu 2017)

\begin{tabular}{|l|l|}
\hline \multicolumn{1}{|c|}{$\begin{array}{c}\text { Type of Mathematics Knowledge } \\
\text { Ball, Thames and Phelps (2008) }\end{array}$} & \multicolumn{1}{c|}{ Examples } \\
\hline Common Content Knowledge & Teach learners to use the term "divide" not the term "cancel" \\
\hline Specialised Content Knowledge & Modified way to prove the Pythagoras Theorem. \\
\hline $\begin{array}{l}\text { Knowledge of Content/ Student } \\
\text { Teaching }\end{array}$ & $\begin{array}{l}\text { How to use software, laptop and projector to teach Mathematics. } \\
\text { How to use strategies for Midpoint Theorem } \\
\text { Learners find it difficult to find a constraint when there is a number. } \\
\text { Team-teaching: how to teach difficult topics }\end{array}$ \\
\hline $\begin{array}{l}\text { Knowledge of Content and } \\
\text { Curriculum (Horizon) }\end{array}$ & $\begin{array}{l}\text { Programme of Assessment from the Mathematics Curriculum. } \\
\text { How to make connections across topics from Grade } 10 \text { to } 12\end{array}$ \\
\hline
\end{tabular}

Table 3 shows the types of teacher knowledge that the mathematics teachers learn from different 
collaborative activities during the workshop and outside of the workshop. The findings from the observation show that collaborative activities were created by the NGO facilitator and mathematics subject advisor. For example, the NGO facilitator would explain or demonstrate the Midpoint theorem then ask teachers to work in groups or in pairs to use their experiences and knowledge to come with a strategy of how to teach that particular topic. The findings show that the main knowledge focus of the workshops is specialised content knowledge.

\section{Common Content Knowledge (CCK)}

According to Hill and Lubienski (2007, 753), CCK includes the ability to identify incorrect answers or inaccurate definitions, and the ability to successfully resolve the students' problems. The findings do not clearly show how the teachers learnt this knowledge separately from other knowledge. The common content knowledge relating to the use of the term "cancel" emerged during the interaction between the teachers. The common content knowledge emerged from a task the focus of which was on specialized content knowledge. For example, when teachers were in groups giving feedback on a task, they said "Learners cancel ..." (Group A). The NGO facilitator interjected because she was concerned about the way teachers use the term "cancelling":

Siza: "The cancelling is a problem, cancelling does not exist. It is a swearing word in mathematics. You do not cancel but you divide."

The NGO facilitator's role was key to the learning of common content knowledge as she is the one who showed the teachers that the term cancel is used incorrectly in mathematics, the correct term is dividing. Contrary to Ball et al. (2008) that division does not require any special knowledge to do it but is common knowledge for everyone who has studied the basics of mathematics high school algebra, the findings suggest that CCK needs to be treated like all the mathematics teacher knowledge because teachers may find it difficult to use it in different mathematics sections.

\section{Specialised Content Knowledge (SCK)}

Similar to Shulman's (1987) notion of PCK, SCK of mathematics includes finding an example, analogy, demonstration, and resources to make a specific mathematical point (Ball et al. 2008). Bongani also reported on his valuable collaborative learning in one of the NGO workshops:

"... Here they showed us a new way. Where we draw the square and inside this square we draw another small square starting from the lines of this other square and we take the midpoint of the 
end square to draw another square which is also inside of the $1^{\text {st }}$ square which is larger. As soon as you draw the $3^{\text {rd }}$ square inside and you look at the drawing, you will see that they form actually four triangles which have a square inside. So instead of using the usual process to prove the theorem, we use four triangles and a square which is more convenient and easier."

In relation to the SCK, the above interview extract seems to tell us that the Mathematics teachers learnt a new and easier way to the prove Pythagoras theorem.

\section{Knowledge of Content and Students/ Teaching (KCS/KCT)}

This is the knowledge that allows an interaction between "specific mathematical understanding and an understanding of pedagogical issues that affect student learning" (Ball et al. 2008, 389407). The findings from interviews and observation show that collaborative activities of the Mathematics TLC afforded teachers opportunities to learn KCS/KCT. For example, in one of the collaborative activities focussing on algebraic linear progression, $\mathrm{KCS} / \mathrm{KCT}$ was learnt with more focus on the understanding of the content in relation to the learners as shown in the following observation extract:

Teacher 2: "Guys, lets us come up with constraints and form the equation."

Teacher 1: "At most it is represented by $1 / 2 x+1 / 3 y$."

Teacher 2: "Next constraint is $1 / 2 x+2 / 3 x \leq 125$. This is what confused learners, let us rather do it on the table for learners not to be confused."

\section{Knowledge of Content and Curriculum (Horizon)}

The findings do not show how the teacher's collaborative activities enhanced this domain of knowledge. This is in line with the literature on teacher knowledge which indicates that different forms of teacher knowledge may not easily be separated from one another (Brodie and Sanni 2014, 190). Although the knowledge of content and curriculum was evident in the moderation workshop as well as in the two content workshops, the findings do not show that they learnt this knowledge collaboratively. They learnt this knowledge from the NGO facilitator and the mathematics subject advisor.

\section{DISCUSSION}

The findings of this study have shown that the mathematics TLC has existed since 2007 with the support of the KZN Department of Education and especially the NGO. This support from the NGO consisted of funding, resources and a facilitator for the workshops. The findings show that the mathematics teachers in the teacher learning community collaborated both during the workshops and outside of the workshops. In response to the first research question the findings 
indicate that collaborative activities during the workshops were created by the NGO facilitator by engaging teachers in group work and pair work. The collaboration and cooperation in this mathematics teacher learning community seem to show openness, trust and support among participants (Forte and Flores 2014). Arends, Winnaar and Mosimege (2017), in their reflection on the Trends in International Mathematics and Science Study (TIMSS) state that many South African mathematics teachers do not fully embrace collaboration with fellow mathematics teacher as a form of support, as generally they are reluctant to do team teaching and lesson observation $(2017,8)$. This study, however, indicates that the teachers in this community initiated team-teaching to support one another and other teachers who were not part of the group. Thus, it seems that the community members have developed sufficiently high levels of trust to support each other in this way. Collaborative cultures that were driving these teachers to initiate team teaching projects seem to be in line with Day's (1999) contention that contrived collegiality and collaborative cultures work together in that the culture of contrived collegiality may act as a motivation towards more collaborative cultures in providing added opportunities for development. Thus, what began as a cluster group that was established by the Department of Education, is now a community of teachers who take the initiative in supporting one another's professional growth.

The findings in this study suggest that the mathematics teachers share the resources and work together on how to best use resources with their learners. Examples of these resources are books, handouts, five laptops and overhead projectors that they were sharing. This sharing among mathematics teachers seems to be in line with the research literature on teacher learning, which suggests that "developing new ways of working is achieved through collaborative acts of meaning making and ways of envisaging term TLC refers to the group of mathematics teachers this as a mediational tool" (Pirtle 2014, 1). Furthermore, the role played by the NGO facilitator in initiating conversation amongst the teachers promoted the creation of more collaborative activities by teachers themselves that might help them to creatively devise ways of delivering quality education and to support one another.

With respect to the second research question and in line with the teacher knowledge analytical tool, the findings indicated that some types of mathematics teacher knowledge were learnt through teachers' collaborative learning to a certain extent, while other types of mathematics knowledge required an expert to assist teachers. The findings indicate that teachers learnt specialized content knowledge, knowledge of content and students/ teaching, from the facilitator and each other. However, there was no evidence from the findings that shows that teachers learnt knowledge of content and curriculum horizon collaboratively. Rather this was acquired through instruction from the NGO facilitator as was the common content knowledge. 
In relation to Brodie and Sanni's (2014) contention that different knowledge is learnt in different contexts, the findings of this study indicate that some teacher knowledge domains can be learnt collaboratively without an expert, and some domains require an expert to facilitate them. The interjection of the NGO facilitator to correct teachers during collaboration suggest that there is a need for quality-lead teacher interactions based on professional knowledge and skills and collegial reflective culture (Jita and Ndlalane 2009, 59). In order to deepen and strengthen their knowledge of specialised content knowledge, the teachers did need an expert, which is a point made by Maistry (2008) in his study of commerce teachers' learning in a community.

\section{CONCLUSION}

This study examined the nature of collaborative activities and teacher knowledge that was learnt from these activities. The findings have shown that involvement of the KZN DoE through the mathematics subject advisor, the teachers and the NGO, enabled teachers to create a strong collaborative learning environment. It came out from the findings that regular collaboration in this learning community has been effective due to the support of the NGO which provided the expert facilitator and learning resources while the Department provided time for workshops. While the Departmental clusters often focus only on administrative tasks such as moderation of school-based assessment, the activities in this learning community focused on specialised content knowledge in particular. It is recommended that facilitators and those leading teacher learning communities should promote collaborative cultures, conversation among teachers as well as a strong focus on different domains of teacher knowledge in order to create meaningful professional learning. Future research could investigate how these teachers in the study translated their knowledge into their classroom practices especially those teachers who were supported with technological resources in their schools.

\section{REFERENCES}

Arends, F., L. Winnaar and M. Mosimege. 2017. Teacher classroom practices and mathematics performance in South African schools: A reflection on TIMSS 2011. South African Journal of Education 37(3): 1-11.

Avalos, B. 2011. Teacher professional development in teaching and teacher education over ten years. Teaching and Teacher Education 27(1): 10-20

Ball, D. L., M. H. Thames and G. Phelps. 2008. Content knowledge: What makes it special? Journal of Teacher Education 59(5): 389-407.

Bantwini, B. D. 2018. Developing a culture of collaboration and learning among natural science teachers as a continuous professional development approach in a province in South Africa. An International Journal of Teachers' Professional Development: 1366-4530.

Brodie, K. and R. Sanni. 2014. "We won't know it since we don't teach it": Interactions between 
teachers' knowledge and practice. African Journal of Research in Mathematics, Science and Technology Education 18(2): 188-197.

Brodie, K. and H. Borko. (Eds.). 2016. Professional learning communities in South African schools and education programmes. HSRC Press: Cape Town.

Butler, D. L., L. Schnellert and K. MacNeil. 2015. Collaborative inquiry and distributed agency in educational change: A case study of a multi-level community of inquiry. Journal Educational Change 16: 1-16.

Chauraya, M. and K. Brodie. 2018. Learning in professional communities: Shift in mathematics teachers' practices. African Journal of Research in Mathematics, Science and Technology 21(3): 223-233.

Chen, W., D. Elechert and A. Asikin-Garmager. 2018. Comparing the effects of teacher collaboration on student performance in Taiwan, Hong Kong and Singapore. Compare: A Journal of Comparative and International Education: 1-16,

Chow, A. W. K. 2016. Teacher learning communities: The landscape of subject leadership. International Journal of Management 30(2): 287-307.

Cohen, L., L. Manion and K. Morrison. 2007. Research methods in education. $6^{\text {th }}$ Edition. London and New York: Routledge Falmer.

Day, C. 1999. Developing teachers: The challenge of lifelong learning. London: Falmer Press.

Dixon, K., Y. Reed and J. Reid. 2013. Supporting teacher educator professional learning about assessment: Insight from the design and the use of a task analysis tool in a first-year Bed. Programme. South Africa Journal of Higher Education 27(5): 1099-1117.

De Clercq, F. and R. Phiri. 2013. The challenges of school-based teacher development initiatives in South Africa and the potential of cluster teaching. Perspectives in Education 31(1): 77-86.

DBE and DHET see Department of Basic Education and Department of Higher Education and Training.

Department of Basic Education and Department of Higher Education and Training. 2011. Integrated Strategic Planning Framework for Teacher Education and Development in South Africa, 20112025. Pretoria.

Department of Basic Education. 2015. Professional learning communities: A Guide for South African schools. Status: May 2015. Pretoria.

Forte, A. M. and M. A. Flores. 2014. Teacher collaboration and professional development in the workplace: A study of Portuguese teachers. European Journal of Teacher Education 37(1): 91105.

Graven, M. 2002. Mathematics teacher learning communities of practice and the centrality of confidence. Unpublished PhD. University of the Witwatersrand, Johannesburg.

Hargreaves, A. 1994. Changing teachers, changing times: Teachers' work and culture in the postmodern age. London: Cassell.

Hill, H. C. and S. T. Lubienski. 2007. Teacher' mathematics knowledge for teaching and school context: A study of California teachers. Educational Policy 21(5): 747-768.

Hurrell, D. P. 2013. What teachers need to know to teach mathematics: An argument for a reconceptualised model? Australian Journal of Teacher Education 38(11): 54-64.

Jita, L. C. and T. Ndlalane. 2009. Teacher clusters in South Africa: Opportunities and constraints for teacher development and change. Perspectives in Education 2(1): 58-68.

Jita, L. C. and M. L. Mokhele. 2014. When teachers clusters work: Selected experiences of South African teachers within the cluster approach to professional development. South African Journal of Education 2(32): 1-15.

Kwakman, K. 2003. Factors affecting teachers' participation in professional learning activities. Teaching and Teacher Education 19: 149-170.

Kennedy, A. 2005. Models of continuing professional development: A framework for analysis. Journal 
of In-service Education 31(2): 235-255.

Krauss, S. and W. Blum. 2012. The conceptualisation and measurement of pedagogical content knowledge in the COACTIV study and their impact on student learning. Journal of Education 56: $45-61$.

Maistry, M. 2008. Transcending traditional boundaries for teacher professional development: Exploring community of practice approach to teacher professional development. Journal of Higher Education (2): 363-374.

Pirtle, S. S. 2014. Implementing effective professional learning communities. SEDL Insight 2(3) Winter. http://www.sedl.org/insights

Pournara, C., J. Hodgen, J. Adler and V. Pillay. 2015. Can improving teachers' knowledge of mathematics lead to gain in learners' attainment in mathematics? South African Journal of Education 35(3): 1-10.

Priestley, M., K. Miller, K. Barrett and C. Wallace. 2011. Teacher learning communities and educational change in Scotland: The Highland experience. British Educational Research Journal 37(2): 265284.

Robutti O., A. Cusi, A. Wilson, B. Jaworski, O. Chapman, C. Esteley, M. Goos, M. Isoda and M. Joubert. 2016. ICME International survey on teachers working and learning through collaboration. ZDM 45(5): 651-690

Rule, P. and V. John. 2011. Your guide to case study research. Pretoria: Van Schaik.

Schnellert, L. M., D. L. Butler and S. K. Higginson. 2008. Co-constructors of data, c-constructors of meaning: Teacher professional development in age of accountability. Teaching and Teacher Education 24(3): 725-750.

Shulman, L. 1987. Professional development: learning from experience. In Common schools, uncommon future: A working consensus for school renewal. New York: Teacher College Press.

William, D. 2007. Changing classroom practices. Educational Leadership 65(4): 36-41.

Zulu, B. 2017. Teacher learning: A case study of two teacher learning communities in KwaZulu-Natal. Unpublished PhD Thesis. School of Education. Pietermaritzburg. University of KwaZulu-Natal. 